\title{
Professores e sindicatos: do associativismo corporativo à organização autônoma
}

\section{Teachers and unions: from corporate associations to autonomous organization}

\author{
Margarita Victoria Rodriguez ${ }^{1}$ \\ Maria Dilnéia Espíndola Fernandes ${ }^{2}$
}

\begin{abstract}
RESUMO
O trabalho analisa a organização sindical dos professores das redes estadual e municipal de ensino em Campo Grande, no estado de Mato Grosso do Sul, no período de 1977 a 2010. O período considerado encerra a divisão do estado de Mato Grosso e consequente criação e implantação administrativa do estado de Mato Grosso do Sul, quando os professores estavam organizados, por força de lei federal, em associações. A partir da promulgação da Constituição Federal de 1988, que dispôs sobre a organização sindical dos servidores públicos, os professores em Campo Grande e no estado de Mato Grosso do Sul se organizaram em sindicatos. Tal organização sindical, ao longo do período, vem passando por alterações significativas, seja pela necessidade dos trabalhadores em educação promoverem/reverem sua estrutura sindical com vistas à sua democratização, seja pelas reformas das políticas educacionais operadas pelo Estado brasileiro. Para tanto, trabalhou-se com a legislação e documentos de âmbito federal, estadual, municipal, documentos do movimento sindical, entrevistas semiestruturadas e a literatura pertinente à temática. Constatou-se que a organização sindical dos professores, se por um lado, vem expressando os conflitos internos da categoria em que ainda operam mecanismos corporativos que têm interferido em seu processo de democratização, por outro lado, vem manifestando as contradições inerentes às relações entre capital e trabalho na esfera do Estado.
\end{abstract}

Palavras-chave: política educacional; sindicalismo docente; Mato Grosso do Sul.

\footnotetext{
${ }^{1}$ Doutora em Educação pela Universidade Estadual de Campinas (UNICAMP). Professora Adjunta da Universidade Federal de Mato Grosso do Sul, Programa de Pós-Graduação em Educação (UFMS/PPGE), Brasil.E-mail: poroyan@uol.com.br.

${ }^{2}$ Doutora em Educação pela UNICAMP. Professora Associada da Universidade Federal de Mato Grosso do Sul, Programa de Pós-Graduação em Educação, Brasil. E-mail: mdilneia@uol.com.br
} 


\begin{abstract}
The article analyses the teachers' union organization in the states and municipal educational systems from Campo Grande, in Mato Grosso do Sul state, in the period between 1977 and 2010. The period considered ends the Mato Grosso State division and, as a result, there is the creation and administrative foundation of Mato Grosso do Sul state, when teachers were organized, because of federal law restrictions, in associations. Since the enactment of the Federal Constitution in 1988, which authorized the trade union organization for the public servants, teachers in the municipality of Campo Grande and in Mato Grosso do Sul state organized themselves in unions. This union organization, in that period, has passed through significant changes; this is the need for education workers in improving/reviewing their union structure for more democratization, or because of education reforms that were operated by the Brazilian State. For this, the article presents federal, state and municipal documents and laws, documents from trade unions, semistructured interviews and the literature from that area. It was noticed that teachers unionism organization expresses, on one hand, the internal conflicts in the category in which corporative mechanisms still operate that interfered in the democratization process; on the other hand, it is has been manifesting the contradictions inherent between capital and work fights in the State sphere.
\end{abstract}

Keywords: education policies; teachers unionism; Mato Grosso do Sul State.

\title{
Introdução
}

O propósito deste trabalho é apresentar, em uma perspectiva histórica, a organização sindical dos trabalhadores em educação, particularmente a dos professores da rede estadual de ensino, no município de Campo Grande, capital do estado de Mato Grosso do Sul. Diante disso, o trabalho se construiu a partir da legislação, documentos e da literatura pertinente à temática.

De fato, a Associação Campo-Grandense de Professores (ACP), atualmente Sindicato Campo-Grandense dos Profissionais da Educação Pública - cuja sigla, ACP foi mantida em homenagem à história da entidade e da categoria de profissionais, foi fundada em 1952 (SINDICATO CAMPO-GRANDENSE DOS PROFISSIONAIS DA EDUCAÇÃO PÚBLICA, 2012, p. 1).

Assim, de acordo com a ACP, sua fundação deu-se em um contexto quando: "o sistema de educação pública passa por dificuldades e obstáculos que podem comprometer a qualidade do ensino ao cidadão, é preciso então unir a classe [sic] destes profissionais para que os interesses da educação e do aprendizado 
prevaleçam" (SINDICATO CAMPO-GRANDENSE DOS PROFISSIONAIS DA EDUCAÇÃO PÚBLICA, 2012, p. 1).

Dessa forma, quando em $1977^{3}$, o estado de Mato Grosso foi territorialmente desmembrado e deu origem ao estado de Mato Grosso do Sul, os trabalhadores em educação, particularmente os professores da rede estadual no município de Campo Grande, já estavam organizados sob a forma de associação.

Assim, foi com a promulgação da Constituição Federal de $1988^{4}$ (BRASIL, 1988) que tais trabalhadores puderam se organizar em nível sindical - como, aliás, se organizou a grande maioria dos professores das redes públicas de ensino desde então no país.

Pontua-se que a organização dos professores da rede estadual de ensino no estado de Mato Grosso do Sul e, particularmente, no município de Campo Grande, embora apresente similaridades nesta organização com o conjunto nacional de professores enquanto categoria profissional, apresenta também singularidades no que tange à estrutura e organização do aparato sindical. Situação que corrobora que,

no caso brasileiro, qualquer tentativa de reconstituir a história do movimento docente deve considerar, antes de mais nada, que as iniciativas nesse sentido têm se desenvolvido, sobretudo, em nível estadual devido ao caráter descentralizado de nosso sistema de ensino (VICENTINI; LUGLI, 2009, p. 96).

Particularmente, no caso dos professores da rede estadual de ensino de Mato Grosso do Sul, no município de Campo Grande, em sua trajetória enquanto categoria profissional, os mesmos têm se mobilizado em razão de suas condições materiais de existência. Tais condições, historicamente, estão premidas pela modernização conservadora da economia a partir dos anos de 1970/1980, que não por acaso, se processou concomitante à expansão dos sistemas públicos estaduais e municipais de ensino e que acentuou a proletarização de camadas médias da sociedade que ascenderam ao exercício do magistério (PESSANHA, 1994; FERREIRA JÚNIOR, 2003).

Quanto à organização e estrutura de aglutinação e/ou mobilização desses trabalhadores, que se transforma ao longo do período de associação para sindi-

${ }^{3}$ O Estado de Mato Grosso do Sul foi criado pela Lei Complementar n. 31, de 11 de outubro de 1977, e sua instalação político-administrativa deu-se em 1979 (BRASIL, 1977).

${ }^{4}$ Até então, não era permitido aos servidores públicos se organizarem em sindicatos (VICENTINI; LUGLI, 2009). 
cato, observa-se que as ações desenvolvidas vão se imbricando entre, primeiro, a associação municipal e, segundo, a partir da sua transformação em sindicato de base municipal com as ações de sua entidade federativa criada em 1979. De fato:

A representação dos professores, no caso do Mato Grosso do Sul, se estrutura preferencialmente no nível municipal, independente da Rede de Ensino em que o professor atua. A representação estadual é apenas derivada para a Federação, a partir do poder concentrado nos sindicatos municipais (GOUVEIA; FERRAZ, 2011, p. 8).

\section{Professores e organização sindical no município de Campo Grande, Estado de Mato Grosso do Sul}

Embora a organização dos professores da rede estadual de ensino no município de Campo Grande remonte ao ano de 1952 com a criação da ACP, de caráter associativista e atualmente seja "constituída pelos professores e especialistas em educação da rede pública, estadual e municipal, ativos e inativos, tendo por finalidade o estudo, a defesa e coordenação dos interesses profissionais da categoria" (SINDICATO CAMPO-GRANDENSE DOS PROFISSIONAIS DA EDUCAÇÃO PÚBLICA, 1993, p. 1), foi, sobretudo, no final dos anos de 1970 que tais trabalhadores se organizaram para enfrentar a expressão sul mato-grossense do Estado patrimonialista e coronelista. Para Biasotto e Tetila,

[...] o magistério da época já se via penalizado pela mescla com profissionais de outras áreas, ingerência política, insegurança no emprego, indigência salarial, sobrecarga de trabalho, anomalias tais que se impuseram sem tréguas ao professorado até o final dos anos setenta (BIASOTTO; TETILA, 1991, p. 17).

De fato, os funcionários públicos, entre eles os professores que viviam e trabalhavam na região sul do estado, passaram a compor a força de trabalho do estado de Mato Grosso do Sul a partir de 1979. Assim esses professores, em 1979, passaram para a "estrutura jurídica que foi consolidando-se em Mato Grosso do Sul" (FERREIRA JÚNIOR, 2003, p. 50). Mas, este mesmo autor lembra que: "no início, o professorado público estadual encontrava-se totalmente 
desamparado quanto à existência de uma legislação que regulamentasse a sua situação funcional e salarial" (FERREIRA JÚNIOR, 2003, p. 50). Dessa forma, a criação (1977) e a implantação (1979) do novo estado da federação não promoveram imediatamente o aparato jurídico com vistas à reprodução dessa força de trabalho, mesmo porque a administração do novo estado, concebida pelo governo ditatorial, se impunha como "Estado Modelo, com vistas à expansão da fronteira agrícola nacional" (FERNANDES, 2001, p. 54) e sua gestão estava pautada nos moldes da administração gerencial (FERNANDES, 2001).

Assim esse modelo de administração pública indicava o aparato jurídico para a composição e contratação de sua força de trabalho, os termos instituídos pela Consolidação das Leis do Trabalho (CLT), conforme assinalou Rocha (1992). Diante disso, o Decreto-Lei n. 102, de 06 de junho de 1979, em suas disposições preliminares, garantiu "regime jurídico aos integrantes do Grupo Ocupacional Magistério [...] e regulamentou o Plano de Carreira do Magistério"; e em seguida, em seu artigo segundo, dispôs que: "Os membros do Magistério serão regidos pela legislação trabalhista" (MATO GROSSO DO SUL, 1979, p. 1).

Esta situação entre terem suas carreiras e salários regidos pela CLT ou por um Estatuto do Magistério esteve entre as primeiras contendas que os professores da rede estadual de ensino enfrentaram com o governo do novo estado. Tal situação foi resolvida com a aprovação da Lei Complementar n. 04, de 12 de janeiro de 1981 (MATO GROSSO DO SUL, 1981) que reenquadrou o grupo do magistério no âmbito do funcionalismo público. Não obstante, este desfecho se deu em razão de estar em vigor a Lei 5.691/1971 (BRASIL, 1971) que indicava concurso público para o ingresso no magistério e também a postura de membros do poder legislativo, cuja postura sinalizava disputas vindouras em torno do poder executivo (ROCHA, 1992).

A conjuntura nacional demarcada pela exaustão da economia política do regime ditatorial que colocou em curso a retomada da democratização política do país espraiou-se também pelo estado de Mato Grosso do Sul, quando os professores da rede estadual de ensino conseguiram se organizar de forma associativa, e criaram, em "sete de abril de 1979, a Federação dos Professores de Mato Grosso do Sul” (BIASOTTO; TETILA, 1991, p. 57).

A criação desta nova entidade de caráter associativista foi possível em razão da unificação de cinco associações municipais de professores da rede estadual de ensino, a saber: a Associação Campo-Grandense de Professores (ACP), a Associação de Professores de Aquidauana (APA), a Associação de Professores de Corumbá (APC), a Associação Pontaporanense de Professores (APP) e a Associação Douradense de Professores (ADP) (BIASOTTO; TETILA, 1991; FERREIRA JÚNIOR, 2003). Essa proposta associativista ganhou adeptos que se encontravam ainda em muitos municípios sem nenhuma organização. Resultou 
desse processo a criação de uma estrutura organizativa de caráter federativo, em razão de que:

\begin{abstract}
Desde as primeiras conversações para a criação de uma Associação em nível estadual todos pensavam em termos daquilo que se conhecia, ou seja, Associação com núcleos regionais, a exemplo da Associação Matogrossense de Professores. Todavia, como muitos participantes das reuniões eram representantes de Associações de Professores já consolidadas nos vários municípios, pessoas jurídicas portanto, foi-se desenvolvendo a ideia de que essas associações deveriam constituir uma federação, ao invés de associação estadual. A ideia vingou, pois a federação evidentemente unia, enquanto a associação estadual desagregava na medida em que o professor podia optar por filiar-se à associação do seu município, à estadual ou às duas. Feita a opção pela criação de uma federação, deixou-se de lado um ante-projeto de estatuto que havia sido proposto pela ACP e elaborou-se um novo, federalizando as associações municipais (BIASOTTO; TETILA, 1991, p. 53).
\end{abstract}

A criação dessa entidade com essa organização e estrutura expressou, por um lado, o consenso possível entre os professores da rede estadual de ensino naquele momento histórico e, por outro, revelou o dissenso entre eles que se encontrava no campo ideológico. De fato:

A Federação dos Professores de Mato Grosso do Sul - FEPROSUL foi fundada, num momento de tensão e disputa entre os professores de Campo Grande, ligados à Associação Campograndense de Professores - ACP e os docentes do interior, principalmente através da Associação Douradense de Professores - ADP e a Associação dos Professores de Aquidauana - APA (TOALDO, 2003, p. 80).

Dividiam-se os professores em duas questões: a primeira, em torno de uma entidade se de caráter combativo ou se uma entidade de natureza colaborativa. A segunda cindia-os o corporativismo e que se manifestava em uma situação de cunho territorial: os professores de Campo Grande entendiam que tinham primazia no que se referia à condução diretiva da nova organização, contudo, estes professores encontravam-se também divididos ideologicamente, pois, "pelo fato dos representantes dos municípios deixarem de lado a proposta da ACP, a sua di- 
retoria resolveu transformar aquela entidade em Associação Sul Mato-Grossense de Professores, à revelia das decisões já tomadas" (BIASOTTO; TETILA, 1991, p. 54). A síntese desse processo se consolidou quando da aprovação do estatuto da Federação de Professores de Mato Grosso do Sul (FEPROSUL), que instituiu a eleição de sua direção pela assembleia geral de delegados.

Cabe considerar que a composição da assembleia geral era de três representantes por município, sem se considerar o número de filiados em cada associação municipal. Essa composição de assembleia foi alvo de várias críticas formuladas principalmente por professores de Campo Grande que estavam vinculados à militância de esquerda - nesse momento histórico tais professores, em razão da ditadura civil militar e do processo político-partidário engendrado por ela -, participavam do arco de aliança política no partido do Movimento Democrático Brasileiro (MDB) e seus partidos políticos de origem eram o Partido Comunista Brasileiro (PCB) e o Partido Comunista do Brasil (PC do B). Não obstante, para Ferreira Júnior esse cenário com

ausência das eleições diretas para a diretoria da FEPROSUL, no contexto político da transição democrática, impedia um avanço de consciência social da categoria profissional dos professores como um todo e fortalecia a tendência de subordinação da sociedade civil a um Estado autoritário. Assim sendo, a FEPROSUL reforçava a "correia de transmissão" que reproduzia a política de exclusão das classes subalternas do direito à cidadania e debilitava o bloco político de oposição à ditadura militar (FERREIRA JÚNIOR, 2003, p. 56).

Ainda assim, os professores da rede estadual de ensino foram protagonistas das maiores greves já registradas no estado de Mato Grosso do Sul nos anos de 1980. De forma que,

todas as greves do magistério matogrossulense [sic] tiveram características semelhantes [...] os professores reivindicaram junto ao governo estadual o pagamento de um piso de 3 salários mínimos [...] e de 4 salários mínimos. O governo, por sua vez, acenava com a possibilidade de pagar 3 salários mínimos, a partir de março do ano seguinte - 1988. [...] pleiteavam também os professores [por] reforma estatutária, eleições diretas para diretor e diretor adjunto, ensino público e gratuito para todos os níveis, verbas públicas somente para escolas públicas. (BIASOTTO; TETILA, 1991, p. 152). 
A conjuntura dos anos de 1980, contudo, colocou outros fatos que marcaram a organização dos professores da rede estadual de ensino tanto no município de Campo Grande como no estado de Mato Grosso do Sul. Registram-se aqui dois episódios que provocaram tal organização em seu limite. O primeiro foi a criação de uma entidade paralela à FEPROSUL pelo governo Pedro Pedrossian - a Associação dos Professores de Mato Grosso do Sul (APMS) -, que "nasceu sem a participação das bases. Parida nas salas palacianas, surgiu para defender os interesses do governo" (BIASOTTO; TETILA, 1991, p. 125). Sobre esse fato ainda a

estratégia governista foi no sentido de redimensionar a correlação de forças do conflito social que mantinha com o movimento sindical dos professores estaduais. [...] desencadeou simultaneamente procedimentos que minaram, ao mesmo tempo, tanto a estrutura sindical da FEPROSUL quanto precipitaram o desfecho da greve, realizando assim uma operação no melhor estilo autoritário do seu caráter político (FERREIRA JÚNIOR, 2003, p. 90-91).

O segundo episódio foi de caráter interno à organização, contudo, fundamental para os rumos que o movimento organizativo dos professores iria assumir depois de seu desfecho. Tratou-se da decisão da entidade se filiar ou não a Central Única dos Trabalhadores (CUT) que havia sido fundada em 1983. A FEPROSUL, embora filiada à Confederação Nacional dos Trabalhadores em Educação (CNTE), que estava filiada à CUT, travou um intenso processo interno de disputas entre suas lideranças sobre essa decisão.

De fato, importantes lideranças do movimento associativista dos professores da rede estadual de ensino estavam divididos sobre a questão de se filiar ou não à CUT. Havia um empenho importante de professores de Campo Grande vinculados ao $\mathrm{PCB}$ e ao $\mathrm{PC}$ do $\mathrm{B}$ pela filiação da entidade à CUT, mas a direção da FEPROSUL, que contava com a maioria dos seus dirigentes filiados ao MDB e que tinha a hegemonia do movimento, encaminhava-se contra essa disposição - embora, como já mencionado, os professores comunistas também estivessem abrigados sob o "guarda-chuva" do MDB no arco de alianças políticas.

Mas esse foi o tempo também da fundação do Partido dos Trabalhadores (PT) em 1980 e no movimento dos professores estaduais houve professores que fizeram essa opção político-partidária. Diante disso, se os professores comunistas se concentravam a maioria em Campo Grande, os professores petistas encontravam-se por todo o estado. Assim o movimento começou a expressar em suas bases as ideias desses novos atores políticos em seu seio e uma delas era a 
defesa da filiação da entidade à CUT. A hegemonia do movimento, todavia, que se expressava em sua direção organizativa, permanecia contrária a essa posição.

Tal contenda foi resolvida tardiamente em 1989, quando da realização do XVI Congresso Estadual da FEPROSUL - instância máxima de decisão da entidade - quando esse Congresso aprovou a filiação da entidade à CUT (FEDERAÇÃO DOS TRABALHADORES EM EDUCAÇÃO DE MATO GROSSO DO SUL, 1989). Nesse momento havia sido construída a hegemonia necessária para que a entidade se filiasse à CUT, fosse porque os professores da rede estadual de ensino filiados aos partidos de esquerda tivessem insistido em tal questão mobilizando pela discussão, fosse porque naquele momento histórico os membros da diretoria ${ }^{5}$ da entidade se movimentassem para outros rumos político-partidários.

Pontua-se que esse Congresso Estadual aprovou outras resoluções importantes com vistas à democratização da entidade, desde sua estrutura à organização. Destaca-se aqui a mudança do nome da entidade de FEPROSUL para Federação dos Trabalhadores em Educação de Mato Grosso do Sul (FETEMS), pois, com a filiação à CUT a entidade encaminhou seus rumos na perspectiva de organizar os trabalhadores em educação por ramo de atividade (FEDERAÇÃO DOS TRABALHADORES EM EDUCAÇÃO DE MATO GROSSO DO SUL, 1989).

Mais uma vez aqui, agora como FETEMS, a entidade encontrou oposição a esta organização pelos professores estaduais do município de Campo Grande, que estavam na ACP. Desta feita, já nos anos 1990, a hegemonia diretiva da ACP estava sob o comando do Partido do Movimento Democrático Brasileiro (PMDB) e tal direção trabalhou contra a unificação dos trabalhadores em educação na mesma base territorial e por ramo de atividade. Se a FETEMS conseguiu unificar os trabalhadores na maioria dos sindicatos municipais no interior do estado por ramo de atividade, não conseguiu tal intento no município de Campo Grande, capital do estado, no maior sindicato em termos numéricos de professores, a ACP.

\footnotetext{
${ }^{5}$ Nessa ocasião era presidente da FEPROSUL o professor Antonio Carlos Biffi o qual exerceu três mandatos (http://www.ptnacamara.org.br/index.php?option=com_content\&view=article\&id=20 1:antonio-carlos-biffi-ms\&catid=48\&Itemid=117/). Ex-integrante do MDB, também remonta a esse período sua filiação ao PT. Sua filiação ao PT foi objeto de intensas polêmicas entre os membros do Diretório Municipal do PT em Campo Grande. Nas duas ocasiões que a filiação do professor compôs a pauta de reunião do Diretório Municipal do PT de Campo Grande, a filiação não foi aprovada. Diante disso, o Secretário Geral do PT de Campo Grande encaminhou tal filiação ao Diretório Estadual do PT onde foi aprovada a filiação do professor (PARTIDO DOS TRABALHADORES, 1990; 1991). O professor foi Secretário de Administração (1999 a 2000) e Secretário de Educação (2001 a 2002) no Governo Zeca do PT (http://pt.wikipedia.org/wiki/Ant\%C3\%B4nio_Carlos_Biffi). Atualmente Antonio Carlos Biffi encontra-se no seu terceiro mandato de Deputado Federal pelo PT (http://biffi.com.br/).
} 
Assim, em Campo Grande, somaram-se à direção da ACP contra a unificação dos trabalhadores em educação por ramo de atividade, setores dos tradicionais especialistas em educação que, mesmo filiados às Federações Nacionais dos Orientadores Educacionais (FENOE) e dos Supervisores de Ensino (FENASE), cujas entidades encaminhavam nacionalmente pela unificação, contrariaram suas entidades representativas.

Pontua-se que em 1991, a política educacional do estado de Mato Grosso do Sul imprimiu mudanças significativas na nomenclatura e função do especialista em educação, quando esse trabalhador passou a ser o coordenador pedagógico e seu trabalho passou a ser o atendimento a alunos e professores por turno na escola e não mais por etapas e/ou modalidades da educação básica (MATO GROSSO DO SUL, 1991).

Tal política marcou também a história conjuntural da ACP durante a segunda metade dos anos de 1980 e primeira metade dos anos de 1990, com a constituição de uma oposição de professores reconhecida pela CUT. Tal oposição, identificada como "Oposição Cutista de Professores de Campo Grande", embora tivesse disputado a direção da ACP por três eleições consecutivas, nunca conseguiu assumir a direção da entidade. Contudo, conseguiu naquele momento histórico fazer disputas importantes com vistas à democratização da entidade em suas relações com a base e também com a FETEMS.

Também naqueles anos foi revista a representação por sindicato na Assembleia Geral da FETEMS, quando se adotou a proporcionalidade como forma de representação das bases municipais nesse fórum (FEDERAÇÃO DOS TRABALHADORES EM EDUCAÇÃO DE MATO GROSSO DO SUL, 1989; 2011).

Outra situação importante com vistas à democratização da FETEMS foi a adoção da proporcionalidade na composição da diretoria entre as forças políticas que por ventura disputassem por meio de eleição a sua direção. Tal situação teve vida curta. Atualmente, no artigo 63 de seu Estatuto vigora que: "A Direção Executiva da Fetems será constituída pela Chapa vencedora das Eleições” (FEDERAÇÃO DOS TRABALHADORES EM EDUCAÇÃO DE MATO GROSSO DO SUL, 2011, p. 22).

Pode se observar que a organização dos professores estaduais no município de Campo Grande, ao tempo que guarda suas singularidades, mantém sua história organizativa e estrutural visceralmente imbricada à organização desses trabalhadores em âmbito estadual. Obviamente que tal desenho foi possível em razão da escolha de organização e estrutura federativa que o movimento, primeiro associativista, e na sequência sindical, optou.

Não obstante, atualmente a FETEMS congrega 71 sindicatos municipais filiados, mais de 22 mil trabalhadores na base e representa $54 \%$ do funcionalismo 
público estadual (FEDERAÇÃO DOS TRABALHADORES EM EDUCAÇÃO DE MATO GROSSO DO SUL, 2012a).

Se a Federação (FETEMS) avançou com vistas à democratização das relações sindicais entre os trabalhadores em educação e destes com o cenário nacional dos trabalhadores organizados, a ACP - direção e base - continua refém de um corporativismo que pode historicamente ser identificado como aquele que "defende a colaboração entre as classes no âmbito das categorias. Sua interpretação da dialética social é otimista, ao passo que as premissas em que se baseia o modelo sindical são conflitantes e pessimistas" (BOBBIO; MATTEUCCI; PASQUINO, 2010, p. 287).

Diante disso, a ACP adentra ao século XXI sem nenhuma alteração em sua estrutura organizativa e o estatuto em vigor é o de 1993, que instituiu em seu artigo terceiro, tendo como organismos e instâncias decisórias a Assembleia Geral, o Conselho de Representantes Sindicais nas Unidades Escolares, a Diretoria Executiva e o Conselho Fiscal (SINDICATO CAMPO-GRANDENSE DE PROFISSIONAIS DA EDUCAÇÃO PÚBLICA, 1993, p. 2). Mas podem-se observar intensas transformações na gestão de seu patrimônio material e imaterial.

No que tange a questão do patrimônio material, foi a partir do final dos anos de 1990 destes anos que sua diretoria se empenhou como nunca na construção e consolidação de seu Clube de Campo, espaço dedicado a eventos tais como "Jantar dançante da primavera, Comemoração do dia das crianças e do professor", etc. (SINDICATO CAMPO-GRANDENSE DE PROFISSIONAIS DA EDUCAÇÃO PÚBLICA, 2012).

Foi também a partir do final dos anos de 1990 e inicio dos anos 2000 que se verificou o empenho do Sindicato em promover ações que congregassem cada vez mais professores e especialistas em educação inativos por meio da "Secretaria dos Aposentados", cujo Secretário compõe a Diretoria Executiva da ACP. Conforme o artigo 15 de seu estatuto, esta Diretoria Executiva é composta por 15 membros, sendo dois deles suplentes (SINDICATO CAMPO-GRANDENSE DE PROFISSIONAIS DA EDUCAÇÃO PÚBLICA, 1993 p. 5-6).

De fato, como argumentaram Gouveia e Ferraz (2011, p. 9-10):

as práticas anteriores a 1988, que eram desenvolvidas pelas antigas associações nacionais, estaduais e municipais de professores, também deixaram suas marcas. [...] a forte estrutura recreativa e mesmo assistencialista de boa parte dos sindicatos de professores é devedora deste passado. 
No campo imaterial, pela natureza da força de trabalho, cresceu o número de sindicalizados - se em 1984 eram 1.508 (FERREIRA JÚNIOR, 2003, p. 53) e em 2003 eram 4.036 (TOALDO, 2003, p. 126), em 2011 eram 4.256 (MIDIAMAX, 2011), filiados à ACP. Tal aumento de sindicalizados deveu-se, sobretudo, ao processo de municipalização do ensino público que, embora induzido pelas políticas de fundos instituídas pelo governo federal a partir de 1996, no estado de Mato Grosso do Sul este movimento se iniciou ainda em 1993 (FERNANDES, 2000; GOUVEIA; FERRAZ, 2011).

Cabe pontuar aqui que, como os professores e especialistas em educação da rede municipal de ensino do município de Campo Grande estão sob a mesma estrutura e organização da ACP que os da rede estadual de ensino, contudo, essa mesma estrutura e organização sindical tem efeitos muito diferenciados para os encaminhamentos entre as lutas, pleitos, reivindicações e qualquer que seja a demanda, dado que os empregadores de um e de outro se diferenciam.

Um caso típico dessas diferenças se expressa na condução do movimento sindical pela direção da ACP em relação à eleição de diretor de unidades escolares. Enquanto que na rede estadual de ensino a eleição para diretor de escolas está em curso desde 1991 (MATO GROSSO DO SUL, 1991), não obstante, tal processo ao longo desses anos tenha apresentado muitas contradições em razão das chefias do poder executivo estadual e das práticas estabelecidas pelas escolas (FERNANDES, 2010), no município de Campo Grande, ainda a nomeação de diretor de escolas tem sido prerrogativa do Prefeito. A mobilização promovida pela ACP entre uma e outra rede em torno dessa questão é distinta: quando conflitos se operam na rede estadual há mobilizações no sentido de garantir eleições de diretores. Para o caso do município de Campo Grande não há questionamentos do sindicato sobre eleição de diretores (SINDICATO CAMPO-GRANDENSE DE PROFISSIONAIS DA EDUCAÇÃO PÚBLICA, 2011), mas há, por parte da política educacional engendrada, o aprofundamento da meritocracia por meio de processos de certificações desde 2001 (RODRIGUEZ et al., 2010).

Outro ponto que merece destaque na relação entre os sindicalizados da ACP com o poder municipal refere-se à política educacional implementada ao longo dos anos para a educação infantil. A educação infantil paulatinamente tem expressado em sua gestão o aprofundamento da relação público e privado. Desde a contratação de professores de forma terceirizada até o repasse de verbas para entidades sem fins lucrativos de caráter não governamental (FUNDAÇÃO CARLOS CHAGAS, 2010). Não há por parte da ACP nenhum questionamento sobre esse processo (SINDICATO CAMPO-GRANDENSE DE PROFISSIONAIS DA EDUCAÇÃO PÚBLICA, 2011). 
Assim, no que tange a estrutura e organização desses trabalhadores em educação, tanto da rede estadual como municipal de ensino, ela permanece a mesma desde 1989 (FEDERAÇÃO DOS TRABALHORES EM EDUCAÇÃO DE MATO GROSSO DO SUL, 1989; 2011). O que mudou durante esse período foi a forma de luta com vistas à mobilização da categoria, principalmente em torno de planos de carreira e remuneração. Observa-se que particularmente entre os anos de 1999 a 2006 - gestão do Partido dos Trabalhadores no Poder Executivo - inicialmente, a categoria apresentou sua luta naquela perspectiva identificada por Ridenti - consideram-se aqui as ressalvas apontadas por esse autor sobre como está caracterizado esse momento histórico - como a da

institucionalização defensiva [...] quando o capitalismo está plenamente estabelecido, predominam as propostas de esquerda defensivas e institucionais em consonância com a opacidade e a complexidade da estrutura de classes, que dificultam sua organização política e até mesmo sindical (RIDENTI, 2006, p. 38).

No período mais recente, embora ainda mantendo as características apontadas pelo autor no plano federal, no plano estadual os trabalhadores em educação tiveram que se haver com a administração do atual governador André Puccinelli (2007 a 2013), um dos impetrantes da Ação de Inconstitucionalidade da Lei 11.738/2008 (BRASIL, 2008), que instituiu o Piso Salarial Nacional Profissional (PSPN). Pontua-se que a luta nacional desencadeada em defesa do PSPN foi promovida pela CNTE com a adesão de suas entidades afiliadas e por isso mesmo, tanto a FETEMS como a ACP vêm encampando esta luta. O curioso é que nos momentos de mobilização em torno do PSPN, como foi em março de 2008, durante os três dias de greve nacional em defesa do PSPN, no município de Campo Grande, aderiram à greve somente os professores da rede estadual, os professores da rede municipal de ensino em momento algum foram mobilizados pela $\mathrm{ACP}$ em torno de matéria da mais alta importância para a categoria (FEDERAÇÃO DOS TRABALHADORES EM EDUCAÇÃO DE MATO GROSSO DO SUL, 2012b).

$\mathrm{Na}$ ampla campanha promovida pela FETEMS na mídia estadual, que convocava os trabalhadores em educação para a greve nacional dos três dias em defesa do PSPN, os trabalhadores em educação das redes estadual e municipal foram identificados como "professores da rede pública de ensino" (MIDIAMAX, 2012). 


\section{Considerações finais}

O propósito deste trabalho foi analisar a trajetória de organização sindical dos professores da rede estadual de ensino no município de Campo Grande. De fato a organização desses trabalhadores se iniciou como de caráter associativista em razão mesmo das condições estruturais e conjunturais que vivia o país e que se expressavam no plano político-ideológico para o conjunto da sociedade.

A retomada da democratização política no país permitiu que tais trabalhadores pudessem, a partir de 1988, se organizar em sindicatos, situação que colocou novos desafios para esses trabalhadores.

No caso dos professores da rede estadual de ensino no município de Campo Grande, o principal desafio que atravessou o período e que ainda está em curso é que a estrutura e organização promovida até então, se por um lado criou as condições históricas e jurídicas para a unificação da categoria por ramo de atividade, por outro lado, a expressão político-ideológica de suas direções não tem permitido que a categoria construa uma perspectiva de sindicato mais abrangente no sentido de reconhecer o pertencimento de todos os trabalhadores da educação.

Outro desafio que permanece é a diferença na condução da luta entre os trabalhadores em educação de uma e outra rede de ensino: enquanto na rede estadual de ensino as lutas e mobilizações desses trabalhadores ganham contornos sindicais, na rede municipal o tom é outro: permanece uma cultura colaboracionista entre os trabalhadores em educação e o poder municipal, o que remete e reforça o caráter associativista da ACP.

\section{REFERÊNCIAS}

BIASOTTO, W. V.; TETILA, J. L. C. O movimento reivindicatório do magistério público estadual de Mato Grosso do Sul: 1978-1988. Campo Grande: UFMS, 1991.

BIFFI, Antonio Carlos. Biografia. Disponível em: <http://biffi.com.br/>. Acesso em: 11/03/ 2012.

BOBBIO, N.; MATTEUCCI, N.; PASQUINO. Dicionário de Política. 13. ed. v. 1. Brasília: UnB, 2010.

BRASIL. Casa Civil. Subchefia para Assuntos Jurídicos. Lei 5.692, de 11 de agosto de 1971. Fixa Diretrizes e Bases para o ensino de $1^{\circ}$ e $2^{\circ}$ graus, e dá outras providências. 
Diário Oficial da União, Brasília, DF, 12 ago. 1971. Disponível em: < http://www.planalto. gov. br/ccivil_03/Leis/L5692.htm>. Acesso em: 20/02/2011.

. Lei Complementar n. 31, de 11 de outubro de 1977. Cria o estado de Mato Grosso do Sul e dá outras providências. Diário Oficial da União, Brasília, DF, 12 out. 1977. Disponível em: <http://br.vlex.com/source/dou-diario-oficial-da-uniao-2080/ issue $/ 1987 / 11 / 11 / 03>$. Acesso em: 03/03/2012.

. Constituição (1988). Constituição da República Federativa do Brasil. Brasília: Senado Federal, 1988.

. Lei n. 11.738, de 16 de julho de 2008. Regulamenta a alínea "e" do inciso III do caput do art. 60 do Ato das Disposições Constitucionais Transitórias, para instituir o piso salarial profissional nacional para os profissionais do magistério público da educação básica. Diário Oficial da União, Brasília, DF, 17 jul. 2008. Disponível em: <http://planalto.gov.br/ccivil_03/_Ato2007-2010/2008/Lei/L11738.htm>.Acesso em: 29/03/2010.

FEDERAÇÃO DOS TRABALHADORES EM EDUCAÇÃO DE MATO GROSSO DO SUL. XVI Congresso Estadual de Amambai. Ata dos Congressos Estaduais da FEPROSUL/1989, fl. 61. 1989.

. Estatuto. Campo Grande, 2011. Disponível em: <http://www.fetems.org.br/novo/ institucional.php?inst=54 >. Acesso em: 08/03/2012.

. Institucional. Plano de Lutas 2011-2012. Campo Grande: 2012a. Disponível em: $<$ http://www.fetems.org.br/novo/institucional.php?inst=18>. Acesso em: 15/08/2012.

. CNTE comemora sucesso da greve nacional. 2012b. Disponível em: < http:// www.fetems.org.br/novo/nw.php?nw=3808 > . Acesso em: 16/09/2012.

FERNANDES, M. D. E. Políticas Públicas de Educação: a gestão democrática na rede estadual de ensino em Mato Grosso do Sul. Campo Grande: UFMS, 2000.

. Políticas Públicas de Educação: o financiamento da rede estadual de ensino de Mato Grosso do Sul (1991 a 1994). 250 f. Tese (Doutorado em Educação) - Faculdade de Educação, Universidade Estadual de Campinas, Campinas, 2001.

FERNANDES, M. D. E. Recentes regulações na gestão da educação básica brasileira: entre o Estado e o mercado. 2010. Disponível em: <http://www.anpae.org.br/iberolusobrasileiro2010/cdrom/76.pdf>. Acesso em: 16/09/2012.

FERREIRA JÚNIOR, A. Professores e sindicalismo em Mato Grosso do Sul (1979-1986). Campo Grande: UFMS, 2003.

FUNDAÇÃO CARLOS CHAGAS. Educação infantil no Brasil-Avaliação qualitativa e quantitativa. Relatório Final. Coordenação Maria Malta Campos. nov. 2010. 424 p.

GOUVEIA, A. B.; FERRAZ, M. Sindicalismo docente e conjuntura política: um estudo comparativo entre o Mato Grosso do Sul e o Paraná. Rio de Janeiro, 2011. Disponível em: <http://nupet.iesp.uerj.br/arquivos/AndreaGouveia.pdf>. Acesso em: 01/09/2012. 
MATO GROSSO DO SUL. Decreto-Lei n. 102 de 06 de junho de 1979. Dispõe sobre o plano de carreiras do magistério e dá outras providências. Diário Oficial do Estado de Mato Grosso do Sul, Ano I, n. 108, Campo Grande, MS, 6 jun. 1979. Disponível em: $<$ http://ww1. imprensaoficial.ms.gov.br/pdf/DO108_06_06_1979.pdf >. Acesso em: 05/09/2012.

. Lei Complementar n. 4, de 12 de janeiro de 1981. Dispõe sobre o Estatuto do Magistério Estadual de Mato Grosso do Sul e dá outras providências. Diário Oficial do Estado de Mato Grosso do Sul, Ano III, n. 505, Campo Grande, MS, 13 jan. 1981. Disponível em: <http://ww1.imprensaoficial.ms.gov.br/pdf/DO505_13_01_1981.pdf>. Acesso em: 05/09/2012.

. Decreto n. 5.868, de 17 de abril de 1991. Dispõe sobre a estrutura básica das unidades escolares da rede estadual de ensino e dá outras providências. Diário Oficial do Estado de Mato Grosso do Sul, Ano XIII, n. 3033, Campo Grande: MS, 18 abr. 1991. Disponível em: <http://ww1.imprensaoficial.ms.gov.br/pdf/DO3033_18_04_1991.pdf >. Acesso em: 05/09/2012.

MIDIAMAX. Sindicato Campo-grandense dos Profissionais da Educação Pública tem eleição nesta sexta-feira. Campo Grande, 16 nov. 2011. Disponível em: <http://www. midiamax.com/SLZ1P/PLgLW/noticias/776309-sindicato+campo+grandense+ profissio nais + educacao+publica+tem+eleicao+nesta+sexta+feira.html $>$. Acesso em: 15/09/2012.

.Em MS, 85\% dos professores aderem à paralisação. Campo Grande, 14 mar. 2012. Disponível em: <http://www.midiamax.com.br/noticias/789410-ms+85+professores+ aderem + paralisacao.html>. Acesso em: 16/09/2012.

PARTIDO DOS TRABALHADORES. Diretório Municipal de Campo Grande. Campo Grande: Atas de Reunião [s.n], 09 set. 1990.

18 abr. 1991.

. Diretório Municipal de Campo Grande. Campo Grande: Atas de Reunião [s.n],

PESSANHA, E. C. Ascensão e queda do professor. São Paulo: Cortez, 1994.

PT na Câmara - Site Oficial da Liderança do PT. Antonio Carlos Biffi (MS). Disponível em: <http://www.ptnacamara.org.br/index.php?option=com_content\&view=article\&id $=201$ : antonio-carlos-biffi-ms\&catid=48\&Itemid=117>. Acesso em: 11/03/2012.

RIDENTI, M. Trabalho, sociedade e os ciclos na história da esquerda brasileira. In: ARAÚJJ, S. M. de; BRIDI, M. A ; FERRAZ, M. (Orgs.). O sindicalismo equilibrista - entre o continuísmo e as novas práticas. Curitiba: UFPR/SCHLA, 2006, p. 23-41.

ROCHA, D. A gestão da educação pública em Mato Grosso do Sul-práticas racionalizadoras e clientelismo. 160f. Tese (Doutorado em Educação) - Pontifícia Universidade Católica de São Paulo. São Paulo, 1992. 
RODRIGUEZ, M. V. et al. Formação e avaliação de diretores de escolas no âmbito da parceria entre municípios e o Instituo Ayrton Senna. Educare et Educere, v. 5, n. 10, p. 163-179, 2010.

SINDICATO CAMPO-GRANDENSE DOS PROFISSIONAIS DA EDUCAÇÃO PÚBLICA. Sobre o sindicato. Disponível em: $<$ http://www.acpms.com.br/?a=sobre $>$. Acesso em: 03/03/2012. . Estatuto. Campo Grande, 1993.

. Destaque. 2011. Disponível em: <http://www.acpms.com.br/enfoque-ver/ enfoque-acp-2011--edicao-16/33>. Acesso em: 15/09/2012.

TOALDO, C. J. O novo sindicalismo e a mobilização dos professores da rede pública estadual sul-mato-grossense: Avanços e Rupturas (1979/1992). 188f. Dissertação (Mestrado em História) - Universidade Federal de Mato Grosso do Sul. Campo Grande, 2003.

VICENTINI, P. P.; LUGLI, R. G. História da profissão docente no Brasil: representações em disputa. São Paulo: Cortez, 2009.

Texto recebido em 14 de setembro de 2012 .

Texto aprovado em 30 de setembro de 2012. 